Heredity (1979), 43 (1), 9-18

\title{
ANALYSIS OF GENETIC CONTROL OF CHYLOUS ASCITES IN RAGGED MICE
}

\author{
MARGARET E. WALLACE \\ Department of Genetics, University of Cambridge
}

Received 24.i.79

\begin{abstract}
SUMMARY
Chylous ascites is a disorder visible as a white fluid in the peritoneal cavity of suckling mice. It is due to inadequate lymphatic drainage from the small intestine. An initial genetic study showed it to be a pleiotropic effect of ragged, $R a$. There were four main studies. These involved seven major mutants segregating with ragged. Four of the mutants had no effect on chylous ascites, but two mutants linked with ragged, and one unlinked, showed a complex situation involving enhancement, inhibition, epistacy and other interactions. The overall phenotypic effects which these mutants are known to have do not explain how they produce their interaction with ragged in terms of chylous ascites. The studies also indicate the existence of a single major modifier controlling penetrance and expression, and there is evidence for cumulatively acting minor modifiers. In neonates the male sex is more liable to chylous ascites, and in adults this condition affects fertility and fecundity.
\end{abstract}

\section{INTRODUCTION}

A LARGE number of inherited conditions in mammals is controlled by major mutants with imperfect penetrance. It has been amply demonstrated that penetrance is controlled by modifiers, but in very few cases has the number of modifiers been investigated, and in only one in the house mouse has the chromosomal location of a modifier been attempted (Wallace, 1972) and established (Wallace, 1976a).

Mouse mutants are increasingly studied as models for inherited conditions in man, dominants being useful because of the ease of maintenance (e.g. yellow, $A^{y}$, and adipose, $A d$, in the study of obesity-see Herberg and Coleman, 1977, and Wallace and MacSwiney, 1979). Yet, although imperfect penetrance is common in mice, and may be expected to mask the existence of major genes in some inherited conditions in man, studies of the control of penetrance in mouse mutants of medical interest have usually gone no further than to show its polygenic nature.

When preliminary evidence of a modifier somewhere in chromosome 2 was obtained for the polygenically controlled dominant condition of chylous ascites in neonatal ragged $(R a)$ mice (Herbertson and Wallace, 1964), it seemed useful to do a selection experiment and to include the ragged gene in two different routinely maintained stocks marked for chromosome 2. This paper reports features of the control of penetrance found, and the location of certain important modifiers.

Chylous ascites is a disorder in which milky fluid is visible through the skin, in the peritoneal cavity of suckling neonatal mice. Investigation has shown (Herbertson and Wallace, 1964) that there is no communication between the lumen of the alimentary tract and the peritoneal cavity, so the 
condition is not due to "leakage" of ingested milk. Rather, it is due to inadequate lymphatic drainage from the small intestine, with resultant build-up of chylous fluid in the peritoneum and of fat droplets in the walls of the small inestine. A chylous ascites condition in human infants has been ascribed to an abdominal lymphdysplasia (Weber, Emons, Knöpfle and Kowalewski, 1975).

Ragged is due to a hair structure defect (Slee, 1957) in which the homozygous neonates show generalised oedema. The cause of the latter is uncertain. Heart failure and endocrine anomaly are suggested by Slee, but his findings do not preclude a fault in lymphatic drainage.

\section{Materials AND MEthods}

\section{(i) Isogenesis experiments}

In the first study (Herbertson and Wallace, 1964), a $R a+$ mouse with chylous ascites, from a colony showing 18 per cent of raggeds so affected, was crossed three times into the standard inbred strain, AG/Cam. A further two back-crosses have since been made. A $R a+$ mouse from a stock described in the same study, but in which no chylous ascites had been seen in over $5000 R a+$ mice, was similarly backcrossed five times into AG/Cam. Five backcrosses of a marker to an inbred line produces a stock in which the whole genotype is the same as (isogenic with) that of the inbred line, except for a small section of chromosome round the marker. Each backcross tends to reduce the length of this section. There being no $R a+$ with chylous ascites in these isogenic stocks, normal $R a+$ mice from each were used in five backcrosses to the stock showing 18 per cent affected $R a+$ Examination for chylous ascites was made throughout.

\section{(ii) Stock segregating for five chromosome 2 markers}

A five-marker linkage experiment described in the first study was completed. There are 16 types of heterozygote; one is multi-coupling (generalised as $A B C D E / a b c d e$ ), and the others are part coupling and part repulsion (e.g. $A B c d e / a b C D E)$. These were represented in both sexes, and mated to the multiple recessive ( $a b c d e / a b c d e$ ), forming "linkage backcross" matings. The data from these, and from their "linkage preparation" matings (e.g. ABcde/abcde $\times a b C D E / a b c d e$ ), were collated. (The design is described in Wallace, 1957, and in Wallace, MacSwiney and Edwards, 1976, and ensures that, when nearly equal numbers of progeny are bred from each linkage backcross type, each pair of markers segregates as often in coupling as in repulsion.) One type of mating is obtained from another by crossing-over, and this process is repeated over several generations. Successive cross-overs between markers tends to dissociate the latter from segregating polygenes in the segments between them. Thus, in the present study, any observed tendency for a marker to interact with the segregation of chylous ascites is likely to be an effect of the marker itself rather than that of polygenic modifiers linked to it.

Chylous ascites was scored throughout. The markers were: ragged, tanbelly, wellhaarig, fidget and Danforth's short-tail, with mutant symbols respectively, and recombination percentages approximately, as follows:

$$
R a-25-a^{t}-12-w e-20-f i-22-S d
$$


The mutants brown ( $b$, chromosome 4), short ear (se, chromosome 9) and polydactyly ( $p y$, chromosome 1) were also segregating. All the mutants except $p y$ are fully penetrant. Data were complete in 1966.

(iii) Stock segregating for three chromosome 2 markers

On completion of the 5-marker study, the mutants we and $a^{t}$ were made homozygous and the other three chromosome 2 markers kept segregating. There are four types of linkage heterozygote with three markers (generalised $A B C / a b c, A b c / a B C, a B c / A b C$ and $a b C / A B c)$. The $b$ and $p y$ mutants were left segregating, but the normal allele of se was made homozygous.

\section{(iv) Stock selected for penetrance of chylous ascites}

In the last two stocks there was no selection for parents with chylous ascites, but at the end of the isogenesis experiment, some ++ mice and some $R a+$ mice, of which many showed chylous ascites, were chosen to start a selection experiment. Preference was given to mice not showing we until this mutant disappeared; $a^{t}$ and $a$ were ignored but gradually $a^{t}$ predominated. A closed colony of about 10 matings was set up, in which preference for $R a+$ mates showing chylous ascites was exercised, these being mated at random to ++ . As matings became infertile, they were replaced, hence there were no distinct generations. Data covered progeny scored from 1965-72.

\section{Results}

\section{(i) Isogenesis experiments}

After the fifth backcross to AG/Cam, none of the $R a+$ mice descended from either the high-incidence or the low-incidence source, showed chylous ascites. During the backcrosses of $R a+$ from these to the high-incidence stock, $R a+$ mice from both sources began to show chylous ascites; and after the fifth backcross, the incidence of chylous ascites in $R a+$ from both sources agreed with that of the high-incidence stock.

In the following tables, chylous ascites is abbreviated to Ch.As. and concerns only the ragged progeny - the equally numerous non-raggeds being omitted from all the data.

\section{(ii) Stock segregating for five chromosome 2 markers}

The linkage backcross and preparation data were collated for the incidence of chylous ascites according to sex, the $a^{t}$ or $a$, the $S d+$ or normal, the $B$ or $b$, and the se or normal genotypes. In some 750 raggeds scored, no relationship with sex or with the alleles at these various loci was found.

The same procedure was carried out for the we, $f i$ and $p y$ segregations. The linkage backcross and preparation data are given in table 1: the $S d$ and $a^{t}$ parts of the genotypes are omitted.* In both types of data the percentage of chylous ascites is doubled in $f i$ as compared with non- $f i$ (24 per cent from 12 per cent). (Part of these data, and the isogenesis result, have been reported (Wallace, 1966).) In the preparation data, we

* There are 468 mice classified in the backcross data, and 427-428 in the preparation matings. Numerical discrepancies are due to deaths before complete classification-notably of fidgets. 


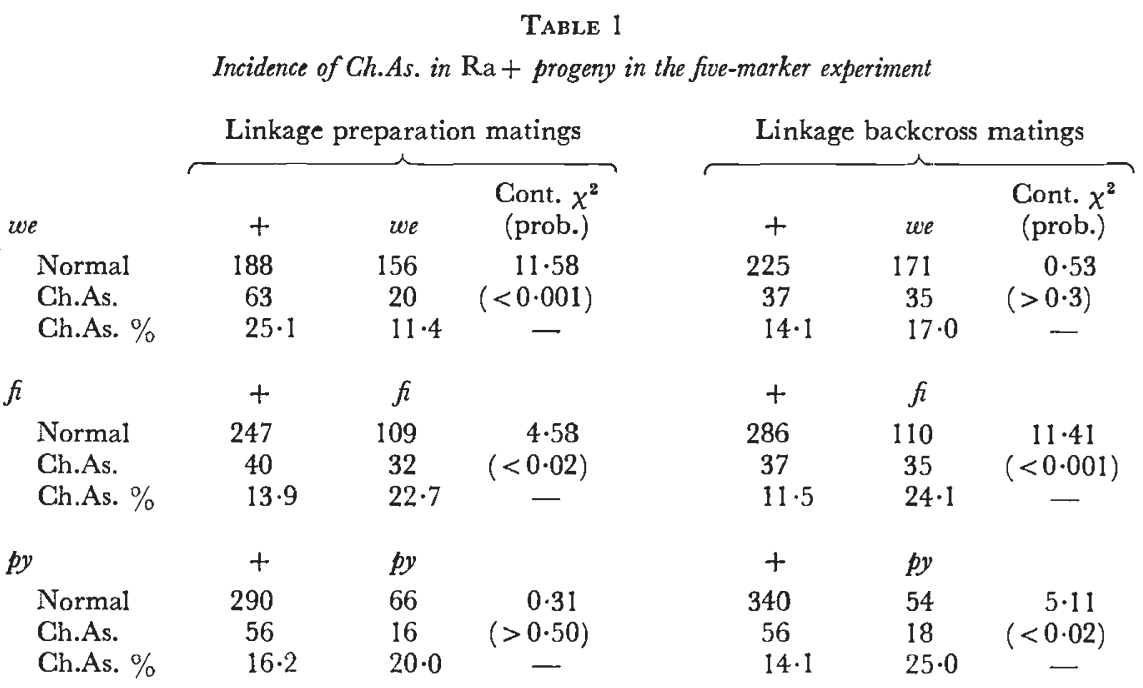

halves the percentage of chylous ascites ( 11 per cent from 25 per cent), but in the backcross data it has no effect. The preparation matings were $w e+w e f i \times+f i / w e f i$ and thus $f i$ segregatéd independently of we and so did not interfere with its action. In the backcrosses, coupling between we and $f$ predominated over repulsion, so that there were more animals homozygous for both we and $f$ than for either separately; it must be that in the homozygotes the enhancing effect of $f$ is epistatic to the inhibiting effect of we.

The paucity of polydactyly is due to imperfect penetrance of $p y$. Fidget is known to enhance the penetrance (Wallace, 1954) and here the effect is strong (not shown): 12.7 per cent of non- $f$ are affected and 22.0 per cent of $f$. Since $f$ enhances the penetrance of chylous ascites, there may be an association between the latter and polydactyly. Table 1 shows chylous ascites to be nearly twice as frequent in polydactylous mice as in normal.

\section{(iii) Stock segregating for three chromosome 2 markers}

These data are larger than those for the five-marker linkage study (1396 $R a+$ progeny classified). As before, $S d$ showed no association with chylous ascites. Fidget, as before, more than doubles the incidence of polydactyly, and just about doubles the incidence of chylous ascites. The mutual enhancement between chylous ascites and polydactyly is now very marked; it cannot be due solely to their common relation to fidget.

From these linkage backcrosses, 280 non-chylous and 102 chylous mice died before fidget could be classified (about 10 days). Thus 9.96 per cent $(139 \div 1396)$ of living mice were affected and $26 \cdot 70$ per cent $(102 \div 382)$ of dead ones (probability of equality is $\ll 0.001$ ). Since the ratio of living non- $f i: f i$ is $898: 498$, the viability of fidget is only 35.67 per cent. Clearly the death of many of the fidgets was due to chylous ascites, and so $f$ enhances the expression as well as the incidence of chylous ascites.

The grand total of $1778 R a+$ progeny analysed in the last paragraph were divided according to parentage, i.e. matings phenotypically $S d-R a$ 우 
TABLE 2

Incidence of Ch.As. in $\mathrm{Ra}+$ progeny in the three-marker linkage backcresses*

A. Raw data

$\begin{array}{lrrrrr} & +,+ & +, p y & f,+ & f i, p y & \text { Totals } \\ \text { Normal } & 792 & 34 & 389 & 42 & 1257 \\ \text { Ch.As. } & 69 & 3 & 52 & 15 & 139 \\ \text { Totals } & 861 & 37 & 441 & 57 & 1396\end{array}$

\begin{tabular}{lcccccc}
\multicolumn{7}{c}{ B. Analysis } \\
& + & $f i$ & $\begin{array}{c}\text { Cont. } \chi^{2} \\
\text { (prob.) }\end{array}$ & + & $p y$ & $\begin{array}{c}\text { Cont. } \chi^{2} \\
\text { (prob.) }\end{array}$ \\
Normal & 826 & 431 & $10 \cdot 56$ & 1181 & 76 & $60 \cdot 54$ \\
Ch.As. & 72 & 67 & $(<0.01)$ & 121 & 18 & $(\ll 0 \cdot 001)$ \\
Ch.As. \% & 8.0 & 13.5 & & 9.3 & $19 \cdot 1$ &
\end{tabular}

Normal

Poly.

Poly. $\%$

$\begin{array}{ccc}+ & f & \begin{array}{c}\text { Cont. } \chi^{2} \\ \text { (prob.) }\end{array} \\ 861 & 441 & 27.37 \\ 37 & 57 & (\ll 0.001) \\ 4 \cdot 1 & 11.4 & \end{array}$

* The linkage preparation data were not collated.

$\times f \sigma^{*}$, and the reciprocal cross, each subdivided according to whether the $R a+$ mate was normal or had chylous ascites. It was found (not shown) that the average output of $R a+$ young dying before 10 days, and those living longer, was not affected by the chylous ascites status of the $R a+$ parent (sexes pooled). However (not shown), the sex of the different phenotypes of parent, regardless of chylous ascites status, was important: the average output of live $R a+$ young by $R a+$ fathers was 11.8 and by $R a+$ mothers $6 \cdot 9$, and the output of progeny dying young was 3.4 for $R a+$ fathers and 1.6 for $R a+$ mothers. These differences were significant, but it is not possible to partition the cause between the $S d+$ and the $R a+$ part of the phenotype. Since the mates of the $S d-R a$ parents were fidgets, who are notoriously bad mothers, the short-tail ragged combination must make for poorer mothers than the fidget phenotype does.

TABLE 3

Incidence of Ch.As. in $\mathrm{Ra}+$ progeny in relation to the Ch.As. status of the parent (Data from three-marker backcrosses)

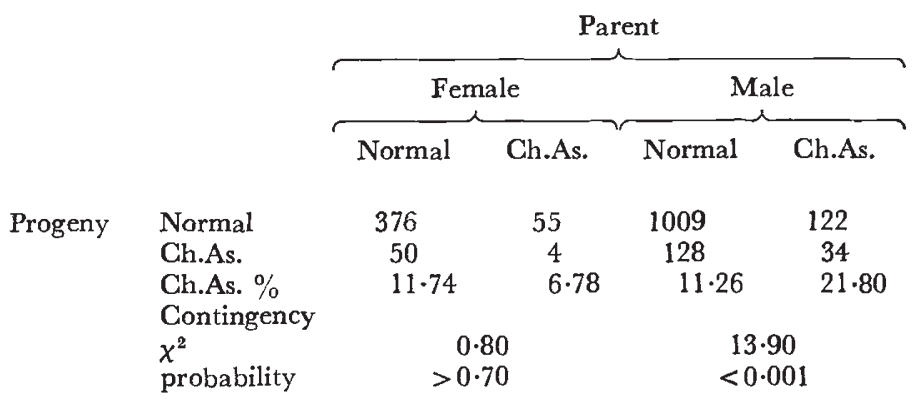


The $1778 R a+$ progeny were next examined for an association between their own affected status and that of their $R a+$ parent. In fidget and nonfidget progeny the trends were the same, so the data are simply given in the eight classes shown in table 3. Chylous ascites fathers have twice as many chylous ascites young as normal ones. Possibly affected mothers' affected young die neonatally, so that the trend for mothers is the same. There was no selection for chylous ascites mice are parents, and affected ones (about 12 per cent of $R a+$ parents) were not more related to each other than to the others, so this relationship must depend on the overt expression of chylous ascites in the parent. Since the effect was not strong in $R a+$ mothers, it cannot be a maternal effect. It appears to be a paternal one.

\section{(iv) Stock selected for penetrance of chylous ascites}

Wellhaarig disappeared from this stock when $218 R a+$ had been bred. Of the 105 we ones, 13 per cent had chylous ascites, and of the 113 non-we ones, 22 per cent had it. The difference is not significant $(P>0 \cdot 1)$, but it confirms that the we gene decreases penetrance of chylous ascites.

Of the $3607 R a+$ bred in this stock, there was, as before, no difference in incidence of chylous ascites between $a^{t}$ and $a$ mice and between the sexes. However, an additional $729 R a+$ died before 7 days; 15 per cent were affected in females and 23 per cent were affected in males (probability of equality is $<0.01$ ). Thus in very young mice the male sex is the more vulnerable to the effects of chylous ascites.

The progress of selection is given in table 4 . The data are grouped into sets of 25 matings (except for the ninth set which consisted of only 17 matings); in the absence of distinct generations, the matings were taken in the chronological order in which the pairs were put together. Their

TABLE 4

Inidence of Ch.As. in $\mathrm{Ra}+$ parents and in $\mathrm{Ra}+$ progeny during selection for Ch.As.

\begin{tabular}{|c|c|c|c|c|c|c|c|c|c|c|c|}
\hline \multirow[b]{3}{*}{$\begin{array}{l}\text { Sets of } 25 \\
\text { matings } \\
(\mathrm{t})\end{array}$} & & & & \multicolumn{8}{|c|}{ Progeny } \\
\hline & \multicolumn{3}{|c|}{ Parents } & \multicolumn{4}{|c|}{ Lived } & \multicolumn{4}{|c|}{ Died } \\
\hline & Normal & $\begin{array}{l}\text { Ch. } \\
\text { As. }\end{array}$ & $\begin{array}{l}\text { Ch. } \\
\text { As. \% }\end{array}$ & $\begin{array}{c}\text { Normal } \\
\left(a^{\prime}\right)\end{array}$ & $\begin{array}{l}\text { Ch. } \\
\text { As. } \\
(a)\end{array}$ & $\begin{array}{l}\text { Total } \\
\mathrm{S}(n)\end{array}$ & $\begin{array}{l}\text { Ch. } \\
\text { As. } \%\end{array}$ & $\begin{array}{l}\text { Normal } \\
\qquad\left(a^{\prime}\right)\end{array}$ & $\begin{array}{l}\text { Ch. } \\
\text { As. } \\
(a)\end{array}$ & $\begin{array}{l}\text { Total } \\
\mathrm{S}(n)\end{array}$ & $\begin{array}{l}\text { Ch. } \\
\text { As. } \%\end{array}$ \\
\hline $1 \mathrm{st}$ & 7 & 18 & 72 & 179 & 39 & 218 & 18 & 83 & 9 & 92 & 10 \\
\hline 2nd & 7 & 18 & 72 & 207 & 52 & 259 & 20 & 59 & 11 & 70 & 16 \\
\hline $3 \mathrm{rd}$ & 7 & 18 & 72 & 304 & 79 & 383 & 21 & 90 & 18 & 108 & 17 \\
\hline 4 th & 17 & 8 & 32 & 373 & 87 & 460 & 19 & 36 & 7 & 43 & 16 \\
\hline 5 th & 16 & 9 & 36 & 453 & 75 & 528 & 14 & 109 & 45 & 154 & 29 \\
\hline 6 th & 19 & 6 & 24 & 396 & 67 & 463 & 14 & 95 & 13 & 108 & 12 \\
\hline 7th & 17 & 8 & 32 & 350 & 116 & 466 & 25 & 86 & 33 & 119 & 28 \\
\hline 8 th & 14 & 11 & 44 & 365 & 140 & 505 & 28 & 58 & 13 & 71 & 18 \\
\hline 9 th & 13 & 4 & 24 & 233 & 104 & 337 & 31 & 23 & 14 & 37 & 38 \\
\hline \multicolumn{12}{|l|}{ (17 matings) } \\
\hline \multirow[t]{2}{*}{ Totals } & 117 & 100 & & 2860 & 759 & 3619 & & 639 & 163 & 802 & \\
\hline & & & & $\mathrm{S}\left(a^{\prime}\right)$ & $\mathrm{S}(a)$ & $\mathrm{S}(n)$ & & $\mathrm{S}\left(a^{\prime}\right)$ & $\mathrm{S}(a)$ & $\mathrm{S}(n)$ & \\
\hline \multicolumn{4}{|c|}{$\begin{array}{l}\text { Het. } \chi^{2}(8 \text { d.f. })=33.51 \\
\text { Probability }<0.001\end{array}$} & \multicolumn{4}{|c|}{$\begin{array}{l}\text { Trend } \chi^{2}(1 \mathrm{~d} . f .)=24.08 \\
\text { Probability } \ll 0.001\end{array}$} & $\begin{array}{l}\text { rend } \chi^{2} \\
\text { robability }\end{array}$ & $\begin{array}{l}\text { d.f.) } \\
\ll 0.00\end{array}$ & $14 \cdot 59$ & \\
\hline
\end{tabular}


output is given in terms of progeny that lived until $a^{t}$ was classified ( 7 days) and progeny that were classified as $R a+$ but died before that age. Mice in which $a^{t}$ or sex was doubtful or unclassified were added to the totals in the last paragraph. The same percentage of parents with chylous ascites could not be maintained throughout (the heterogeneity $\chi^{2}$ for the normal: affected ratio has $\mathrm{P}<0.001$ ); this is because of variation in the proportion of chylous ascites progeny that died and so were not available as parents).

A test of significance of the upward trend in the progeny of both live affected and dead affected, is that of R. A. Fisher (quoted in Wallace, 1957) in which, in addition to the symbolism given in the table,

and then

$$
\begin{gathered}
q=S\left(a^{\prime}\right) / S(n), \quad p=S(a) / S(n), \quad t=1,2,3 \ldots 9 \\
S\left(t \times a^{\prime}\right)=A^{\prime} ; \quad S(t \times a)=A ; \\
S(t-\bar{t})^{2}=S\left(t^{2} n\right)-\frac{\{S(t n)\}^{2}}{S n}
\end{gathered}
$$

$$
\chi^{2}=\frac{\left(q A-p A^{\prime}\right)^{2}}{p q S(t-\bar{t})^{2}}
$$

Both trend $\chi^{2}$ values are highly significant. There is thus a very significant upward trend in the incidence of chylous ascites in both living and dead progeny; this proves that selection increased penetrance and that as penetrance increased, so also did expression.

The $R a+$ progeny of this experiment were next summarised into classes that survived 7 days and that died before 7 days, subdivided into normal and chylous ascites, and listed according to whether each sex of their $R a+$ parents was normal or had chylous ascites. The effect of parental phenotype on affected status of progeny was the same in surviving and nonsurviving progeny, and there was no difference between sexes of parents. However, when survivors and non-survivors and male and female parents were pooled (table 5) there was a significant tendency of affected parents to produce affected progeny. This trend was small, a change in penetrance of 20 per cent to 23 per cent. The total effect of selection is much larger table 4 shows a change in penetrance from the first to the ninth set of matings of about 15 per cent to 32 per cent. It is also small compared with the large father/progeny relationship in the three-marker study (described at the end of the last section above.) Probably the modifiers operating in the two studies are different.

Table 5

Incidence of Ch.As. in $\mathrm{Ra}+$ progeny in relation to the Ch.As. status of the $\mathrm{Ra}+$ parent. (Data from the selection stock)

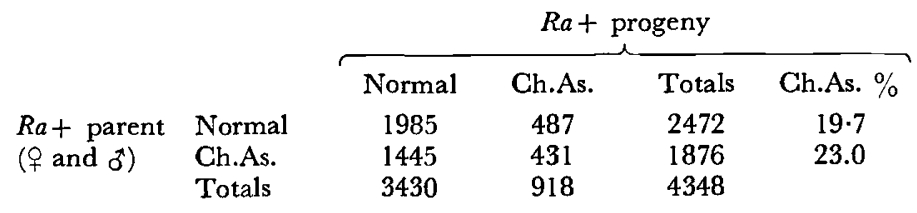

Contingency $\chi^{2}$ for 1 d.f. $=6 \cdot 86, P<0 \cdot 01$. 


\section{TABLE 6}

Fertility and fecundity in $\mathrm{Ra}+$ and Ch.As. phenotypes. (Data from the selection stock)

\begin{tabular}{|c|c|c|c|c|}
\hline$\sigma^{2}$ & $\begin{array}{l}\text { Ra }+ \text { Ch.As. } \\
++ \text { normal }\end{array}$ & $\begin{array}{l}R a+\text { normal } \\
++ \text { normal }\end{array}$ & $\begin{array}{l}++ \text { normal } \\
R a+\text { Ch.As. }\end{array}$ & $\begin{array}{c}++ \text { normal } \\
R a+\text { normal }\end{array}$ \\
\hline Percentage of females & & & & \\
\hline fertile & $58 \cdot 88$ & $72 \cdot 73$ & $78 \cdot 26$ & $82 \cdot 50$ \\
\hline Average litter size & $5 \cdot 62$ & $6 \cdot 35$ & 6.74 & 6.98 \\
\hline Average No. litters & $3 \cdot 43$ & $5 \cdot 23$ & 6.46 & 0.07 \\
\hline
\end{tabular}

The effect of chylous ascites in the parents was next examined in terms of fertility and of output of progeny (fully classified, including non- $R a$ ). The results are given in table 6 . On all criteria, the efficiency of different phenotypes of parent is, in ascending order: $ᄋ R a+C h . A s$, $+R a+$ normal, ${ }^{\star} R a+C h . A s,{ }^{\star} R a+$ normal. The litter size differences were not significant; but the percentage fertile animals and the number of litters per monogamous mating, do vary significantly between the four types $(P<0.02$ and $\mathrm{P}<0.001$ respectively). It thus appears that in females their chylous ascites status, and to a lesser extent their $R a+$ genotype even when normal decrease fertility and fecundity.

\section{Discussion}

\section{(i) The case for pleiotropy}

The disappearance of chylous ascites in $R a+$ mice, from both highincidence and low-incidence stocks, on isogenesis with AG/Cam, shows that incidence is not controlled by a $C h y$ gene linked with $R a$, but by modifiers in the rest of the genotype. Control by modification of $R a$, rather than linkage of Chy, is confirmed by the reappearance of chylous ascites when normal ragged AG/Cam mice were backcrossed to the high-incidence stock. Chylous ascites was never seen in non- $R a$ in the rest of the present study, which is contrary to expectations were there a Chy gene which could have combined with non- $R a$ by crossing-over. It seems therefore that the condition is a pleiotropic effect of ragged, and the symbol Chy suggested in the earlier study (Herbertson and Wallace, 1964) is withdrawn. This view is further confirmed by the finding that an allele of ragged, ragged opossum, $R a^{o p}$, also occasionally shows chylous ascites in heterozygotes (Mann, 1963).

\section{(ii) The effect of major mutants on the incidence of chylous ascites}

The Danforth's short-tail, agouti, brown and short-ear loci are eliminated in the two linkage studies as affecting chylous ascites. The effect of sex is negligible throughout, except in so far as in neonatal mice (as shown in the selection experiment) the male sex is slightly more vulnerable to the deleterious expression of chylous ascites than is the female.

Fidget, or a portion of chromosome very close to it, is a potent modifier in its own right. In both linkage studies it doubled penetrance. As would be expected as a corollary, fidget also increased expression, especially in the three-marker study, to the point of causing death. Fidget enhanced 
polydactyly in both experiments, as expected from previous work. Interaction between polydactyly and chylous ascites is demonstrated in both linkage studies; there can be no doubt that they mutually enhance each other's penetrance.

Fidget has many skeletal effects, such as an abnormal shape of the auditory capsule, a tendency to preaxial polydactyly, and fusion of certain head bones: it also has some presumably secondary effects such as absence of mandibular canal and lachrymal glands (Gruneberg, 1963). Polydactyly is clearly a skeletal anomaly (Holt, 1945), while chylous ascites is a defect of the lymphatic system (Herbertson and Wallace), 1964. It is not at all clear why these mutants should interact. It can only be suggested that fidget and polydactyly in some way upset the homeostasis of the individual, and thus they have rather non-specific effects in developmentally remote tissues.

The effect of wellhaarig is somewhat surprising also. When fidget segregated independently of it, it halved the penetrance of chylous ascites, but when they appeared together fidget eliminated, or was epistatic to, the action of wellhaarig. The inhibiting effect of wellhaarig is seen in all the studies where it segregated. The physiological connection between a hair-waving gene and a defect of the lymphatic system is unknown. However, some recessive hair-waving genes depress viability (Wallace, unpublished); they therefore have more severe effects elsewhere than in the hair. This would not be the first case in which an interaction between apparently diversely acting genes has become understood on closer examination (cf. the relation between short-ear, sex and hydronephrosis, Wallace, $1976 b)$.

\section{(iii) The effect of genes without mutant phenotypes on the penetrance of chylous ascites}

The clear effect that the chylous ascites status of the fathers (and perhaps the mothers) had on that of the offspring, in the three-marker study, and the fact that this is much less clear in the selection work, suggests that there is a single enhancing gene in the former work which does not segregate in the latter. This gene cannot have full penetrance; when present in the ragged parent, it doubles the penetrance of chylous ascites in the ragged progeny, but it does not raise it to a level where a single major gene could be segregating in backcross or intercross fashion. One must therefore conclude that it has imperfect penetrance. Even in the absence of fidget, the selection experiment was successful, and in the last generations penetrance was about 30 per cent - higher than fidget alone had achieved in the other work. As this change is not appreciably correlated with the chylous ascites status of individual parents, it must be concluded that one or more genes with minor effect on chylous ascites, and no visible phenotypic effect in any other respect, were at work. Penetrance of chylous ascites is thus complexly controlled.

\section{(iv) Factors, including their affected status, influencing the output of ragged animals}

The chylous ascites status of $R a+$ parents did not affect their average output per mating (three-marker study). However the ragged status of $43 / 1-\mathbf{B}$ 
mothers reduced their output of both living and neonatally dead young; their mates were fidget, and the implication is that the $S d-R a$ combination makes for poorer mothers than does fidget, although fidget is notorious in this respect. Ragged mothers, not obviously having chylous ascites when young, may show internal complications when adult (see below), and this, together with the skeletally shortening effect of $S d$, crowding the abdominal organs, may well combine to reduce the capacity of the uterus. The poor mothering ability of fidget is due largely to their deafness when mouthing squeaking young (Wallace, quoted in Noirot, 1972), and is thus a different mechanism.

The selection experiment where fidget was absent showed that the fertility of mothers with chylous ascites is seriously impaired. After the disappearance of the condition in maturing young, there remains a complex of fibrous adhesions between the internal organs of affected animals; in the females this probably restricts the movements of the growing uterus and thus limits its capacity to house implanted foetuses - there is some suggestion of this in the earlier work (Herbertson and Wallace, 1964, p. 18). The explanation of the results in table 6 of the selection work may be in these terms. When the adhesions are not severe enough to prevent growth of any young, they may be severe enough to restrict litter size. If they cause increasing rigidity of the internal organs with age, they could then decrease the litter-bearing life of a chylous ascites mother. The inheritance and expression of chylous ascites, as shown by all these studies taken together, is much more complex than at first appeared.

\section{REFERENCES}

Gruneberg, H. 1963. The Pathology of Development. Blackwell, Oxford.

HERBERG, L., AND COLEMAN, D. I. 1977. Laboratory animals exhibiting obesity and diabetes syndromes. Metabolism, 26, 59-64.

Herbertson, в. M., AND WAllace, M. E. 1964. Chylous ascites in newborn mice. Journal of Medical Genetics, 1, 10-23.

hоLт, s. в. 1945. A polydactyl gene in mice capable of nearly regular manifestation. Annals of Eugenics, 12, 220-249.

MANN, s. J. 1963. The phenogenetics of hair mutants in the house mouse: Opossum and Ragged. Genetical Research, Cambridge, 4, 1-11.

NOіRот, E. 1972. Ultra sounds and maternal behaviour in small rodents. Developmental Psychobiology, 5, 371-387.

SLEE, J. 1957. The morphology and development of ragged-a mutant affecting the skin and hair of the house mouse. Fournal of Genetics, 55, 100-121.

wallace, M. E. 1954. Studies in mouse genetics. Ph.D. thesis, pp. 32, 33.

WALI_ACE, M. E. 1957. A balanced three-point experiment for linkage group $\mathrm{V}$ of the house mouse. Heredity, 11, 223-258.

wallace, M. E. 1966. Chylous ascites in ragged. Mouse Newsletter, 35, 16.

WALlACE, M. E. 1972. A single gene isolated from a modifier complex in the mouse. Genetica, 43, 597-606.

wallace, м. E. 1976a. A modifier mapped in the mouse. Genetica, 46, 529.

WAllace, м. E. 1976b. Hydronephrosis in the mouse: The effects of the short-ear gene, sex and ureteral vascular system. American Fournal of Anatomy, 147, 19-32.

WAllace, M. E., AND MACswiney, F, M. 1979. An inherited mild middle-aged adiposity in wild mice. Journal of Hygiene, Cambridge 82, 309-317.

WAllace, M. E., MACsWiney, F, M., AND EDWARDS, R. G. 1976. Parental age and recombination frequency in the house mouse. Genetical Research, Cambridge, 28, 241-251.

WEBER, EMONS, KNÖPFLE, AND KOWALEWski. 1975. Congenital chylöser ascites. Klinische Padiatrie, 187, 370-376. 